\title{
Exportações do Rio Grande do Norte: estrutura, vantagens comparativas e comércio intra-indústrial
}

Jorge Luiz Mariano da Silva ${ }^{1}$

Daniel Borja Valdez Montalván²

Resumo: O presente trabalho tem como objetivo analisar o comportamento e a estrutura do setor exportador do Rio Grande do Norte no período de 1996 a 2006 e identificar os produtos com vantagens comparativas reveladas. Também procura mensurar os graus de concentração de produtos e os destinos das exportações, o tipo de comércio e os setores fortes da pauta de exportações. Para o alcance de tais objetivos, utilizaram-se os índices de comércio intra-industrial, de GRUBEL e LLOYD (1975), e os índices de vantagem comparativa revelada, de BALASSA (1965) e LAURSEN (1998). Os indicadores de concentração de produtos e destino das exportações derivaram do coeficiente de GiniHirchman. Os dados utilizados foram obtidos no sistema ALICEWEB, do Ministério do Desenvolvimento, Indústria e Comércio - MDIC. Os resultados encontrados revelaram alta concentração em poucos produtos primários e mercados de destinos, além da fraca participação de produtos manufaturados exportados. O estudo ainda apontou que o comércio internacional do Estado é basicamente interindustrial, ou seja, exporta produtos primários e importa manufaturas, caracterizando um comércio do tipo Herckscher-Ohlin. Entre os grupos de produtos com comércio intra-industrial, destacou-se o grupo do algodão, um sinal da importância do setor têxtil na economia estadual.

\footnotetext{
${ }^{1}$ Professor do Mestrado em Economia da UFRN

${ }^{2}$ Mestrando do Programa de Pós-Graduação em Economia da UFRGS
} 
Palavras-Chave: Vantagem Comparativa Revelada; Comércio IntraIndústria; Concentração das Exportações.

Classificação JEL: F100, F110, F140.

Abstract: The objective of the present paper is to examine the behavior and the structure of the export sector of the economy of Rio Grande do Norte from 1996 to 2006, and to identify the products of revealed comparative advantage. The paper also seeks to measure levels of export concentration of products and destination markets, types of trade, and export sectors that show strength. To achieve the objectives of the paper, the intra-industry indices of GRUBEL AND LLOYD (1975) and the indices of revealed comparative advantage of BALASSA (1965) e LAURSEN (1998) were used. The indexes of product concentration and export destination were obtained through the Gini-Hirchmna coefficient. The data was taken from the ALICEWEB system of the Ministry of Development, Industry and Trade - MDIC. The results revealed a high concentration of few primary products and destination markets, along with weak participation in the export of manufactured products. The study points out that the international trade of the State of Rio Grande do Norte is basically inter-industrial; that is, it exports primary products and imports manufactured products, characteristic of the Herckscher-Ohlin trade type. Among the group of products with intraindustrial trade, the cotton group stands out, showing the importance of the textile sector in the state's economy.

Key-words: Revealed Comparative Advantage; Intra-Industry Trade; Export Concentration.

JEL Classification: F100, F110, F140.

\section{Introdução}

A história da formação econômica do Nordeste deixa evidente o quanto os estados dessa região colocam-se na dependência da participação da agricultura como geradora de alimentos, de emprego, 
de renda, e mesmo como determinante da própria dinâmica de sua economia. O principal impulso econômico da região era o setor exportador, constituído, basicamente, dos produtos da Zona da Mata e do Semi-Árido, entre os quais se destaca o açúcar, o algodão, o cacau, o fumo, os couros e peles, alguns minérios e algumas oleaginosas. Ao longo de toda a fase da economia agroexportadora, o crescimento do produto regional, para a maioria dos estados, esteve apoiado nas exportações desses produtos. Essa é a fase do crescimento para fora, com um componente exógeno, ou seja, a demanda externa pelos produtos da região. Atualmente, os estados possuem uma estrutura produtiva mais diversificada e a dinâmica de suas economias não depende, unicamente, do multiplicador do comércio exterior. Há, também, um componente endógeno ao país, que influencia na geração da renda e do emprego regional. Indicadores recentes das exportações nordestinas revelam uma queda na participação destas no produto regional, mostrando, de certa forma, que as vendas ao exterior têm contribuído muito pouco para o crescimento regional.

Em se tratando do Rio Grande do Norte, constata-se que a pauta das exportações de sua economia está basicamente concentrada em poucos produtos primários. Dentro dessa perspectiva, para definir uma estratégia de maior inserção dos estados da região Nordeste no comércio internacional, é necessário identificar os produtos com maiores vantagens comparativas. É nesse contexto que o presente trabalho tem como objetivo identificar os produtos exportados pelo Rio Grande do Norte com vantagens comparativas reveladas no período de 1996 a 2006. Pretende-se, ainda, analisar o grau de concentração de produtos e de destinos das exportações, o tipo de comércio intra ou interindustrial e os setores fortes da pauta de exportações do Estado.

Em seguida a essa introdução, na seção 2, descreve-se a evolução dos principais produtos exportados pelo Estado e a distribuição das exportações por blocos econômicos. Na seção 3, descrevem-se os aspectos teóricos e metodológicos utilizados no estudo. Na seção 4, são apresentados os resultados dos indicadores de vantagens comparativas, concentração de produtos e destinos das exportações, e o tipo de comércio exterior do Estado. Na última seção, descrevem-se as considerações finais do trabalho. 


\section{Evolução dos principais produtos da pauta de exportações da economia potiguar}

Ao longo de sua história, a economia do Rio Grande do Norte caracterizou-se pela produção e comercialização de produtos com baixa intensidade tecnológica. Sendo assim, as exportações dos produtos potiguares, de acordo com a composição de fatores no comércio exterior, sempre estiveram caracterizadas pela significativa participação de produtos intensivos em recursos naturais e em trabalho. A cana-de-açúcar, por exemplo, um dos produtos da atividade agrícola estadual, padece com a falta de investimentos no setor, a baixa produtividade e a alta sazonalidade na absorção da mão-de-obra, problemas que são compartilhados por outros estados produtores no Nordeste. Mesmo assim, esse produto tem se sobressaído entre os principais exportados pelo Estado.

Nas décadas de 1980 e 1990, surgem novos produtos na pauta de exportações do Estado, principalmente os produtos da fruticultura irrigada, destacando-se a produção de melão, de banana, de mamão, de manga e de melancia. No final da década de 1990 e início dos anos 2000, o melão chegou a ser o principal produto na linha das exportações. No início dos anos 2000, destacam-se as exportações de camarões e óleo bruto de petróleo. A criação de camarão em cativeiro, estimulada pela ótima adaptação da espécie Litopeneaus vannamei e pela melhoria do preço internacional, cresceu vertiginosamente no litoral potiguar. Isso permitiu um visível aumento nas exportações de camarão, conferindo ao Estado o título de principal produtor nacional.

A Tabela 1, a seguir, apresenta a evolução na estrutura das exportações do Rio Grande do Norte, segundo os principais grupos de produtos da pauta, de acordo com a NCM (Nomenclatura Comum do MERCOSUL). Observa-se que os grupos de produtos com maiores participações no total das exportações foram os de açúcares; frutas; peixes-crustáceos; e, mais recentemente, o grupo de combustíveis. Não obstante, registra-se uma relativa queda na participação dos grupos dos açúcares e frutas entre 1996 e 2006. Constata-se, por outro lado, o crescimento de dois grupos - o de combustíveis e o de peixes-crustáceos - que refletiram mudanças na estrutura das exportações do Estado. As exportações do segundo grupo (de peixes-crustáceos), cujo destaque é a exportação de 
camarão, apresentaram um crescimento significativo a partir de 2000, mesmo enfrentado uma crise no setor em decorrência da imposição de políticas anti-dumping por parte dos Estados Unidos e da queda do preço internacional. Relativamente aos combustíveis e derivados, a sua grande participação no total das exportações deu-se a partir de 2002 em decorrência dos investimentos realizados pela empresa Petrobras no Estado.

As mercadorias estão classificadas por grupos de produtos de acordo com a Nomenclatura Comum do Mercosul (NCM).

Tabela 1 - Estrutura das exportações totais do Rio Grande do Norte por grupos de produtos entre 1996-2006. Em (\%)

\begin{tabular}{|c|c|c|c|c|c|c|c|c|c|c|c|}
\hline $\begin{array}{l}\text { Capítulos/ } \\
\text { período }\end{array}$ & 1996 & 1997 & 1998 & 1999 & 2000 & 2001 & 2002 & 2003 & 2004 & 2005 & 2006 \\
\hline $\begin{array}{l}03 \text { Peixes, } \\
\text { Crustá- } \\
\text { ceos }\end{array}$ & 5,45 & 5,68 & 4,18 & 6,53 & 15,41 & 22,92 & 30,32 & 28,81 & 17,91 & 19,03 & 16,04 \\
\hline 08 Frutas & 41,90 & 40,68 & 46,55 & 43,77 & 32,74 & 29,66 & 27,69 & 29,10 & 17,98 & 31,91 & 38,89 \\
\hline $\begin{array}{l}15 \text { Gordu- } \\
\text { ras }\end{array}$ & 2,65 & 1,56 & 0,21 & 1,39 & 1,24 & 2,27 & 1,85 & 1,50 & 0,89 & 1,35 & 0,42 \\
\hline $\begin{array}{l}17 \text { Açúca- } \\
\text { res }\end{array}$ & 25,42 & 23,03 & 18,83 & 17,45 & 11,34 & 14,27 & 9,51 & 7,99 & 4,51 & 7,91 & 12,04 \\
\hline 25 Sal & 2,44 & 4,25 & 6,86 & 6,76 & 5,98 & 5,75 & 4,07 & 2,63 & 1,30 & 3,05 & 3,61 \\
\hline $\begin{array}{l}27 \text { Com- } \\
\text { bustíveis }\end{array}$ & 0,00 & 0,00 & 0,00 & 0,00 & 0,00 & 0,00 & 10,76 & 18,99 & 49,55 & 23,44 & 7,52 \\
\hline $\begin{array}{l}52 \text { Algo- } \\
\text { dão }\end{array}$ & 4,05 & 5,23 & 4,56 & 4,68 & 1,83 & 2,63 & 2,06 & 2,52 & 1,93 & 3,00 & 2,66 \\
\hline $\begin{array}{l}61 \text { Ves- } \\
\text { tuário de } \\
\text { malha }\end{array}$ & 0,00 & 0,87 & 4,95 & 9,55 & 24,71 & 16,66 & 9,55 & 4,24 & 2,03 & 2,76 & 2,01 \\
\hline $\begin{array}{l}\text { Outros } \\
\text { produtos }\end{array}$ & 18,1 & 18,7 & 13,86 & 9,87 & 6,75 & 5,84 & 4,19 & 4,22 & 3,9 & 7,55 & 16,81 \\
\hline TOTAL & 100,00 & 100,00 & 100,00 & 100,00 & 100,00 & 100,00 & 100,00 & 100,00 & 100,00 & 100,00 & 100,00 \\
\hline
\end{tabular}

Fonte: Elaboração dos autores. Dados disponibilizados pelo MDIC/SECEX, sistema ALICEWEB.

A Tabela 2 mostra o destino das exportações do Rio Grande do Norte, segundo os blocos comerciais e as regiões. Como se pode observar, a maioria das exportações do Estado tem como destino os blocos da 
União Européia e NAFTA (Acordo de Livre Comércio da América do Norte). Nos últimos dois anos mais de $70,00 \%$ das exportações tinham como destino os países pertencentes a esses blocos.

Por outro lado, destaca-se a participação da Comunidade e Mercado Comum do Caribe - CARICOM - como mercado consumidor das exportações de óleos brutos de petróleo, que, em 2004, chegou a representar 98,38 $\%$ do valor exportado desse produto. Nesse âmbito, os três blocos têm uma participação de 83,6 \% no total exportado pelo Rio Grande do Norte em 2006, refletindo uma grande concentração das exportações do Estado em relação ao destino por blocos ou regiões. Constata-se, ainda, a pouca importância dos mercados mais dinâmicos em termos de crescimento econômico, caso da China e dos “Tigres Asiáticos”, e, também, do MERCOSUL (Mercado Comum do Sul) nos destinos das exportações do Rio Grande do Norte.

Tabela 2 - Exportações do Rio Grande do Norte por blocos econômicos entre 1996-2006. Em (\%)

\begin{tabular}{|c|c|c|c|c|c|c|c|c|c|c|c|}
\hline $\begin{array}{l}\text { Blocos/ } \\
\text { Período }\end{array}$ & 1996 & 1997 & 1998 & 1999 & 2000 & 2001 & 2002 & 2003 & 2004 & 2005 & 2006 \\
\hline $\begin{array}{l}\text { União } \\
\text { Européia }\end{array}$ & 37,99 & 36,27 & 41,07 & 32,36 & 34,15 & 33,14 & 34,25 & 36,58 & 24,74 & 39,34 & 42,06 \\
\hline Nafta & 34,13 & 27,70 & 21,74 & 36,02 & 45,90 & 46,15 & 45,13 & 37,54 & 22,49 & 34,01 & 33,69 \\
\hline Mercosul & 4,84 & 9,12 & 12,94 & 7,49 & 5,15 & 4,09 & 2,00 & 2,08 & 1,65 & 3,49 & 3,28 \\
\hline Caricom & 0,00 & 0,02 & 0,00 & 0,01 & 0,01 & 0,01 & 5,78 & 11,11 & 30,60 & 14,10 & 7,87 \\
\hline $\begin{array}{l}\text { Ásia (Ex- } \\
\text { clusive } \\
\text { Oriente } \\
\text { Médio) }\end{array}$ & 1,99 & 0,67 & 0,46 & 3,02 & 0,65 & 0,87 & 0,87 & 0,59 & 0,44 & 1,36 & 0,69 \\
\hline $\begin{array}{l}\text { Tigres } \\
\text { Asiáticos }\end{array}$ & 1,20 & 0,48 & 0,39 & 0,30 & 0,18 & 0,10 & 0,20 & 0,15 & 0,14 & 0,21 & 0,09 \\
\hline $\begin{array}{l}\text { Comuni- } \\
\text { dade An- } \\
\text { dina De } \\
\text { Nações }\end{array}$ & 2,28 & 3,42 & 5,22 & 1,64 & 0,97 & 0,90 & 0,77 & 2,10 & 1,43 & 1,96 & 1,65 \\
\hline África & 13,96 & 17,87 & 14,83 & 14,48 & 7,99 & 9,52 & 6,53 & 3,99 & 1,39 & 4,17 & 1,37 \\
\hline $\begin{array}{l}\text { Liga Ára- } \\
\text { be }\end{array}$ & 2,68 & 0,61 & 0,46 & 2,84 & 0,23 & 2,67 & 2,08 & 0,32 & 0,69 & 0,42 & 4,26 \\
\hline Outros & 0,94 & 3,83 & 2,89 & 1,84 & 4,77 & 2,55 & 2,39 & 5,53 & 16,45 & 0,94 & 5,03 \\
\hline Total & 100,00 & 100,00 & 100,00 & 100,00 & 100,00 & 100,00 & 100,00 & 100,00 & 100,00 & 100,00 & 100,00 \\
\hline
\end{tabular}

Fonte: Elaboração dos autores. Dados disponibilizados pelo MDIC/SECEX, sistema ALICEWEB. 


\section{Indicadores de vantagem comparativa, grau de concentração, e tipo de comércio}

Para alcançar os objetivos do presente estudo, utilizou-se o coeficiente de Gini-Hirchman a fim de mensurar a concentração de produtos e o destino das exportações. Em seguida, utilizaram-se dois índices de vantagens comparativas: o VCR - índice de vantagem comparativa revelada - de BALASSA (1965) e o VCS - índice simétrico de vantagem comparativa de LAURSEN (1998), com o intuito de caracterizar os produtos com vantagens comparativas. E com a pretensão de avaliar se o comércio exterior do Rio Grande do Norte caracteriza-se como inter ou intraindustrial, recorreu-se ao índice de comércio intra-indústria de GRUBEL E LLOYD (1975). Vale explicitar que a base de estudo utilizada na mensuração desses índices e na realização da análise da estrutura das exportações do Rio Grande do Norte foi obtida no sistema ALICEWEB do Ministério do Desenvolvimento, Indústria e Comércio - MDIC, Secretaria do Comércio Exterior - SECEX.

\subsection{O coeficiente de concentração das exportações: o índice de Gini- Hirchman}

O coeficiente de Gini-Hirchman é comumente utilizado para mensurar a concentração das exportações, tanto em relação aos produtos quanto aos mercados de destino. Esse coeficiente é também empregado como uma medida de concentração industrial. Quanto mais concentradas as exportações em poucos produtos e em poucos países, mais a economia estará sujeita às flutuações de demanda, o que implicará mudanças bruscas na receita das exportações. O índice de concentração por produtos (ICP), de acordo com LOVE (1979), é calculado como mostrado na seguinte expressão:

$$
I C P=\sqrt{\sum_{i}\left[\frac{X_{i j}}{X_{j}}\right]^{2}}
$$


Em que $X_{i j}$ representa as exportações do bem i pelo país j, e $X_{j}$ representa as exportações totais do país j. O valor desse índice está definido no intervalo entre 0 e 1 . Quando um país apresenta índice ICP elevado significa que este tem as suas exportações concentradas em poucos produtos. Por outro lado, um índice ICP baixo reflete maior diversificação de produtos na pauta das exportações. Nesse caso, argumenta-se que o país terá uma maior estabilidade nas receitas cambiais. De acordo com LOVE (1979), uma pauta de exportações mais diversificadas pode significar também indício de trocas mais estáveis. Segundo HIDALGO e MATA (2004), diversos fatores determinam o grau de diversificação das exportações: o nível de desenvolvimento econômico, que reflete estruturas de produção mais complexas; a proximidade a pólos comerciais; e o tamanho da economia. Uma economia pequena tem menos possibilidades de produzir, em grande escala, uma maior variedade de produtos; assim, apresentará um ICP maior.

O índice de concentração por países de destino, ICD, mede o grau de concentração das exportações entre os países importadores. Esse índice é calculado da seguinte maneira, segundo LOVE (1979, p. 61):

$$
I C D=\sqrt{\sum_{i}\left[\frac{X_{i j}}{X_{j}}\right]^{2}}
$$

Nesse caso, $\mathrm{X}_{\mathrm{ij}}$ representa as exportações do país j para o país i, e $\mathrm{X}_{\mathrm{j}}$ representa as exportações totais do país j. Um índice de ICD alto significa que um número pequeno de países tem uma importância muito grande na pauta das exportações desse país. Por sua vez, um ICD baixo reflete uma participação mais equilibrada nos diversos mercados. Em tal circunstância, o país estará menos sujeito às flutuações na receita de suas exportações.

De forma complementar, pode-se afirmar que uma concentração alta significa, para uma determinada economia ou região, uma vulnerabilidade maior a choques de demanda. Assim, um baixo nível de concentração dos destinos de suas exportações parece ser desejável para uma determinada economia ou região. 


\section{2 Índices de vantagens comparativas}

Com a finalidade de identificar os produtos potiguares com vantagens comparativas no comércio exterior, foram utilizados o índice de Vantagem Comparativa Revelada (VCR), de BALASSA (1965), e o índice Simétrico de Vantagem Comparativa Revelada (VCRS), de LAURSEN (1998). De acordo com HILDALGO e MATA (2004), o índice de VCR é uma medida revelada, tendo seu cálculo baseado em dados observados após a realização do comércio. Esses índices não levam em consideração a presença de distorções na economia, como as restrições tarifárias e não tarifárias, subsídios, acordos comerciais e desalinhamentos de câmbio, que podem afetar os resultados dos índices. Entretanto, eles servem para descrever os padrões de comércio de uma determinada economia.

Sendo assim, o índice de vantagens comparativas de BALASSA (1965) calcula a participação das exportações de um dado produto de uma economia em relação às exportações de uma zona de referência desse mesmo produto, e compara esse quociente com a participação das exportações totais dessa economia em relação às exportações totais da zona de referência. Para o presente trabalho, o Brasil será utilizado como zona de referência.

Considere-se, então, que o índice de vantagem comparativa revelada para uma região, ou país j, em um setor industrial ou grupo de indústrias i, pode ser definido da seguinte forma:

$$
V C R_{i j}=\frac{X_{i j} / X_{i z}}{X_{j} / X_{z}}
$$

No presente estudo, j representa o Estado do Rio Grande do Norte e z é a zona de referência; no caso, o Brasil. Verticalizando a leitura, entende-se que, $\mathrm{X}_{\mathrm{ij}}$ é o valor das exportações do produto i do Rio Grande do Norte, e $\mathrm{X}_{\mathrm{iz}}$ é o valor das exportações brasileiras do produto i. $\mathrm{X}_{\mathrm{j}}$ é o valor total das exportações do Estado e $\mathrm{X}_{\mathrm{z}}$ é o valor total das exportações do país. Se o índice de $\mathrm{VCR}_{\mathrm{ij}}>1$, então a região j possui vantagem comparativa revelada no produto i; e se o índice de $\mathrm{VCR}_{\mathrm{ij}}<1$, a região apresenta desvantagem comparativa revelada no produto i. O índice simétrico de vantagem comparativa revelada é dado por: 


$$
V C S_{i j}=\frac{V C R_{i j}-1}{V C R_{i j}+1}
$$

Veja-se que os valores desse índice variam entre -1 e +1 . Se o valor do $\mathrm{VCS}_{\mathrm{ij}}$ se encontrar entre +1 e 0 , então a região j possui vantagem comparativa revelada no produto i. Para valores do $\mathrm{VCS}_{\mathrm{ij}}$ entre -1 e 0 , a região apresenta desvantagem comparativa revelada no produto i.

\section{3 Índice de comércio intra-indústria}

Ao longo da história econômica potiguar, o fluxo do comércio exterior foi dominado pelas exportações de produtos primários, intensivos em recursos naturais e em mão-de-obra, e pelas importações de produtos manufaturados com certo grau de componente tecnológico. Essas relações comerciais foram vitais para a manutenção de um comércio teorizado como interindustrial.

Entretanto, em anos recentes, predomina um ambiente cada vez mais globalizado e integrado. O fluxo comercial é caracterizado por um crescente comércio intra-indústria, o qual pode ser definido como a troca de produtos classificados dentro de um mesmo setor. Sendo assim, o conhecimento desse comércio é importante na formulação de estratégias de inserção internacional para uma economia como a do Rio Grande do Norte.

Um indicador que permite classificar se o comércio exterior é do tipo interindustrial ou intra-industrial é o índice de comércio intra-indústria (CIIA), desenvolvido por GRUBEL e LLOYD (1975). Esse índice é aplicado por produto ou indústria, e para toda a economia. Dessa forma, o índice agregado do comércio intra-indústria para toda a economia do Rio Grande do Norte é representado por:

$$
C I I A=1-\frac{\Sigma_{i}\left|X_{i}-M_{i}\right|}{\Sigma_{i}\left(X_{i}+M_{i}\right)}
$$

Em que $\mathrm{X}_{\mathrm{i}}$ representa as exportações do produto i e $\mathrm{M}_{\mathrm{i}}$ representa as 
importações deste pelo Rio grande do Norte. O valor numérico desse índice encontra-se no intervalo entre zero e a unidade. Quando o CIIA iguala-se a 0, deparamo-nos com um comércio do tipo inter-industrial, ou, em outras palavras, o comércio à la Heckscher-Ohlin. Por outro lado, se o CIIA é igual a 1, então todo o comércio é do tipo intra-indústria. De maneira análoga, o índice de comércio intra-indústria (CIIA) em nível de cada indústria ou produto i é apresentado por:

$$
C I I A_{(i)}=1-\frac{\left|X_{i}-M_{i}\right|}{\left(X_{i}+M_{i}\right)}
$$

\section{Resultados obtidos}

Nesta seção, são apresentados os resultados da concentração de produtos e mercados de destino, das medidas de vantagens comparativas e do tipo de comércio internacional do Rio Grande do Norte. A Tabela 3, a seguir, registra os resultados dos índices de concentração por grupos de produto e mercados de destino, além do valor e da taxa de crescimento das exportações. No que se refere à evolução das exportações, constata-se que apesar de uma ligeira queda em 1997, as exportações do Rio Grande do Norte têm crescido ao longo dos anos. Em 2006, o valor exportado atingiu 391,6\% das exportações realizadas em 1996. Quanto ao grau de concentração de produtos, o ICP indicou uma significativa concentração das exportações em poucos produtos durante o período analisado. A classe desse índice variou entre 0,41 a 0,56. Valores próximos ao encontrado por FARIAS (2000), que, utilizando esse mesmo índice, verificou um crescimento de 0,45 a 0,52 na concentração de produtos exportados pelo Rio Grande do Norte no período de 1980 a 1995.

Com respeito à concentração por blocos econômicos, os resultados assinalaram um maior grau de concentração das exportações. A classe desse índice variou, no período, entre 0,55 a 0,60. Um reflexo de que a maior parte das exportações do Estado estava associada a poucos blocos econômicos. Nesse sentido, o setor exportador está sujeito às condições de demanda dos países pertencentes a esses blocos. 
Tabela 3 - Exportações, índice de concentração por produto e por mercados de destinos. Rio Grande do Norte (1996-2006)

\begin{tabular}{ccccc}
\hline Anos & $\begin{array}{c}\text { Exportações (US\$ } \\
\mathbf{1 . 0 0 0})\end{array}$ & $\begin{array}{c}\text { Crescimento das } \\
\text { Exportações } \mathbf{1 9 9 6}=\text { base }\end{array}$ & ICP $^{\mathbf{1}}(\mathbf{\%})$ & ICD $^{\mathbf{2}}(\mathbf{\%})$ \\
\hline 1996 & 94.875 & 100,0 & 0,51 & 0,54 \\
1997 & 93.536 & 98,6 & 0,49 & 0,51 \\
1998 & 101.748 & 107,2 & 0,52 & 0,51 \\
1999 & 115.473 & 121,7 & 0,49 & 0,52 \\
2000 & 149.391 & 157,5 & 0,46 & 0,58 \\
2001 & 187.584 & 197,7 & 0,44 & 0,58 \\
2002 & 223.602 & 235,7 & 0,45 & 0,58 \\
2003 & 310.445 & 327,2 & 0,46 & 0,56 \\
2004 & 573.602 & 604,6 & 0,56 & 0,60 \\
2005 & 413.317 & 435,6 & 0,45 & 0,55 \\
2006 & 371.503 & 391,6 & 0,45 & 0,57 \\
\hline
\end{tabular}

FONTE: Elaboração dos autores. Dados disponibilizados pelo MDIC/SECEX, sistema ALICEWEB. Notas: (1) ICP - Índice de concentração de produtos; (2) ICD - Índice de concentração por blocos econômicos.

Os dados da Tabela 4 e o Gráfico 1, a seguir, mostram os grupos de produtos com vantagem comparativa revelada. Uma região possui vantagem comparativa revelada em um determinado produto quando o valor do VCR for maior que a unidade. De acordo com os valores da tabela referida, para o período analisado, o Rio Grande do Norte apresentou vantagem comparativa revelada nos seguintes grupos de produtos: peixes, crustáceos e moluscos; frutas, cascas de cítricos e melões; açúcares e produtos de confeitaria; sal, enxofre, pedras, gesso e outros; combustíveis; algodão; vestuário e seus acessórios de malha. É importante notar que entre 2002 e 2005, o Estado apresentou um indicador de vantagem comparativa revelada nas exportações do grupo de combustíveis. Entretanto, apenas recentemente, o Rio Grande do Norte passou a exportar esse grupo de produtos, em decorrência do aumento da extração de petróleo pela Petrobras nesse Estado. A maior parte dessas exportações é óleo bruto de petróleo que, em 2006, sofreu uma queda no volume exportado e no indicador de vantagem comparativa.

Os valores do índice de vantagem comparativa apresentaram uma grande variabilidade, que dificulta a comparação entre os produtos. $\mathrm{O}$ 
índice simétrico de vantagem comparativa impõe limites de valores, isto é, entre -1 e +1 . A Tabela 5 e o Gráfico 2, a seguir, mostram os grupos de produtos em que o Rio Grande do Norte possui vantagem comparativa simétrica. Os resultados dessa tabela confirmam que os grupos de produtos com vantagem comparativa são peixes, crustáceos e moluscos; frutas, cascas de cítricos e de melões; açúcares e produtos de confeitaria; sal, enxofre, pedras, gesso e outros; óleos e derivados; e algodão. Em 2006, com a queda nas exportações do grupo de combustível o Estado apresentou uma queda no indicador de vantagens comparativa simétrico. Já em 1996, não realizou exportações do grupo de produtos vestuário e seus acessórios de malha. Consequentemente, a partir de 1997, e anos subseqüentes, os valores desse índice foram maiores do que zero, caracterizando uma trajetória de vantagens comparativas.

Os valores do índice agregado de comércio intra-indústria para o Rio Grande do Norte foram calculados de acordo com a equação 5. Para cada grupo de produto, foi obtido o valor absoluto do saldo comercial, isto é, o valor das exportações menos importações daquele grupo de produtos. Da mesma forma, para cada grupo de produtos foi obtido o valor da soma das exportações e importações. Vale lembrar que se obtém o escore do comércio intra-indústria subtraindo-se da unidade o resultado da divisão desses dois valores. Também se faz relevante lembrar que quando o escore do índice de comércio intra-indústria for próximo a zero, significa que a região tem um baixo nível de comércio intra-indústria, ou seja, o comércio é do tipo inter-indústria. Se o valor do índice se aproximar da unidade, o comércio daquela região será do tipo intra-indústria. De acordo com os dados mostrados na Tabela 6 e no Gráfico 3 subseqüentes, nota-se que o comércio exterior do Estado se caracteriza como interindustrial. Os valores do índice apresentaram-se muito baixos para todo o período analisado. Isso se torna evidente quando se verifica que, no ano de 2006, o valor foi de 0,08. Portanto, apenas $8 \%$ do comércio exterior do Rio Grande do Norte se caracteriza como intraindustrial. O restante, $93 \%$, pode ser considerado interindustrial. Com efeito, o Estado exporta mais produtos primários (básicos) e importa produtos manufaturados, revelando um comércio interindustrial do tipo Heckscher-Ohlin. 
Tabela 4 - Grupos de produtos com vantagem revelada (VCR) - Rio Grande do Norte (1996-2006)

\begin{tabular}{|c|c|c|c|c|c|c|c|c|c|c|c|}
\hline \multirow{2}{*}{ Capítulos } & \multicolumn{11}{|c|}{ Índice de Vantagem Comparativa Revelada (VCR) } \\
\hline & 1996 & 1997 & 1998 & 1999 & 2000 & 2001 & 2002 & 2003 & 2004 & 2005 & 2006 \\
\hline $\begin{array}{l}\text { 03. Peixes e } \\
\text { crustáceos, } \\
\text { moluscos, etc }\end{array}$ & 21,2 & 27,3 & 20,4 & 24,9 & 37,4 & 49,3 & 54,7 & 51,1 & 41,5 & 57,7 & 62,7 \\
\hline $\begin{array}{l}0.8 \text { Frutas, } \\
\text { cascas de } \\
\text { cítricos e de } \\
\text { melões }\end{array}$ & 67,5 & 71,6 & 81,2 & 64,8 & 48,8 & 49,8 & 45,3 & 42,2 & 29,3 & 55,7 & 77,0 \\
\hline $\begin{array}{l}\text { 17. Açúcares } \\
\text { e produtos de } \\
\text { confeitaria }\end{array}$ & 7,3 & 6,5 & 4,7 & 4,2 & 4,8 & 3,5 & 2,6 & 2,5 & 1,5 & 2,3 & 2.6 \\
\hline $\begin{array}{l}\text { 25. Sal, } \\
\text { enxofre, } \\
\text { terras, pedras, } \\
\text { gesso, cal, } \\
\text { cimento }\end{array}$ & 7,8 & 13,2 & 18,1 & 14,6 & 11,5 & 12,5 & 8,5 & 4,7 & 2,6 & 6,7 & 7,7 \\
\hline $\begin{array}{l}27 . \\
\text { Combustíveis, } \\
\text { óleos e ceras } \\
\text { minerais etc. }\end{array}$ & - & - & - & - & - & - & 2,2 & 3,6 & 10,8 & 3,9 & 1,0 \\
\hline 52. Algodão & 6,8 & 11,2 & 10,2 & 11,1 & 3,8 & 3,7 & 3,8 & 3,5 & 2,5 & 4,5 & 5,4 \\
\hline $\begin{array}{l}\text { 61. Vestuário } \\
\text { e seus } \\
\text { acessórios de } \\
\text { malha }\end{array}$ & - & 4,5 & 26,3 & 42,6 & 74,2 & 57,9 & 48,2 & 17,8 & 9,9 & 16,8 & 17,2 \\
\hline
\end{tabular}

FONTE: Elaboração dos autores. Dados disponibilizados pelo MDIC/SECEX, sistema ALICEWEB. As mercadorias estão classificadas por grupos de produtos de acordo com a Nomenclatura Comum do Mercosul (NCM). O símbolo (-) sigunifica ausência de exportações.

A Tabela 6 ainda contém valores do índice de comércio intra-indústria para o Brasil, para o Nordeste, e para Pernambuco. É possível constatar que os valores desse índice para essas economias são bem mais altos do que aqueles constatados para o Rio Grande do Norte. Em outras palavras, as economias pernambucanas, nordestinas e brasileiras têm um comércio internacional com característica intraindustrial. Segundo a literatura, o comércio intra-industrial é explicado pela diferenciação de produtos, diversificação e pelas economias de escala ${ }^{3}$. Essas características são

${ }^{3}$ Ver HIDALGO e MATA (2003) para maiores detalhes. 
mais presentes em produtos manufaturados e estes têm uma menor participação na pauta de exportações do Rio Grande do Norte.

\section{Gráfico 1 - Índice de Vantagem Comparativa Revelada - VCR do Rio Grande do Norte (1996-2006).}

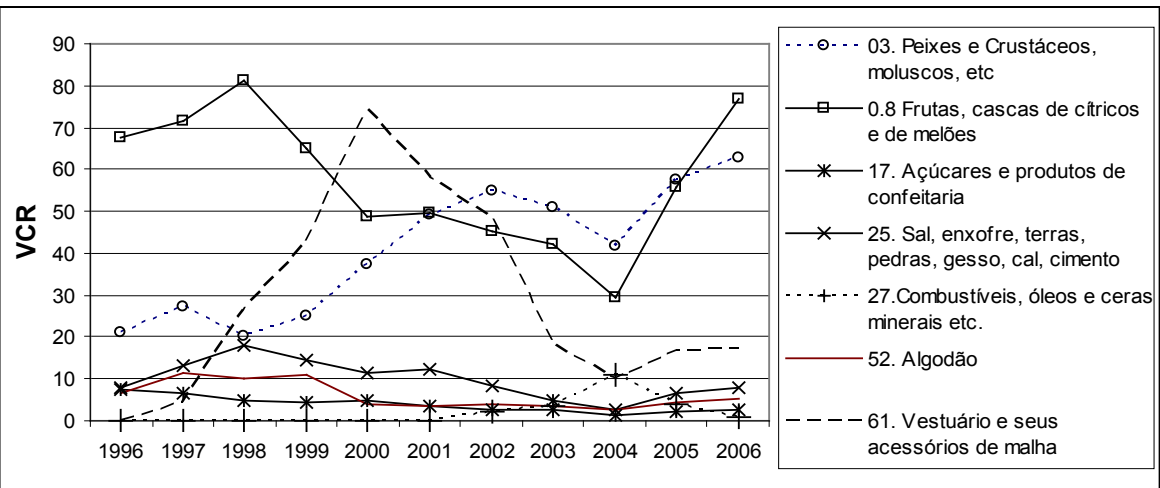

Fonte: Elaboração dos autores. Dados disponibilizados pelo MDIC/SECEX, sistema ALICEWEB. As mercadorias estão classificadas por grupos de produtos de acordo com a Nomenclatura Comum do Mercosul (NCM).

Gráfico 2 - Índice de Vantagem Comparativa Simétrica - VCS do Rio Grande do Norte (1996-2006)

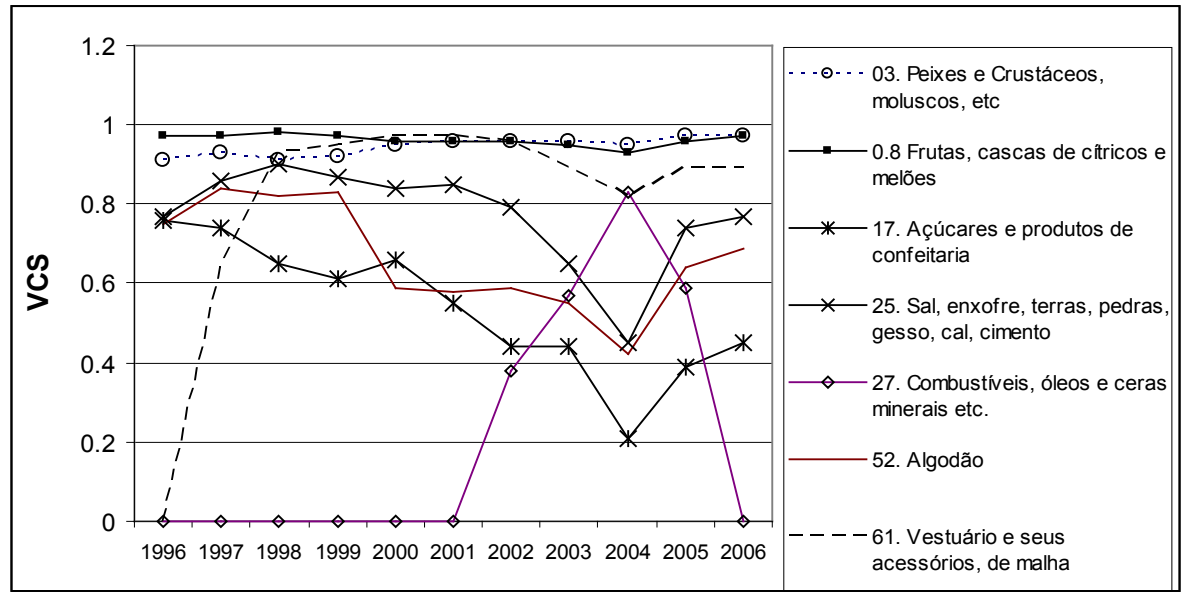

Fonte: Elaboração dos autores. Dados disponibilizados pelo MDIC/SECEX, sistema ALICEWEB. As mercadorias estão classificadas por grupos de produtos de acordo com a Nomenclatura Comum do Mercosul (NCM). 
Tabela 5 - Grupos de produtos com vantagem comparativa simétrica (VCS). Rio Grande do Norte (1996-2006).

\begin{tabular}{|c|c|c|c|c|c|c|c|c|c|c|c|}
\hline \multirow{2}{*}{ Capítulos } & \multicolumn{11}{|c|}{ Índice Simétrico de Vantagem Comparativa (VCS) } \\
\hline & 1996 & 1997 & 1998 & 1999 & 2000 & 2001 & 2002 & 2003 & 2004 & 2005 & 2006 \\
\hline $\begin{array}{l}\text { 03. Peixes e } \\
\text { Crustáceos, } \\
\text { moluscos, etc }\end{array}$ & 0,91 & 0,93 & 0,91 & 0,92 & 0,95 & 0,96 & 0,96 & 0,96 & 0,95 & 0,97 & 0,97 \\
\hline $\begin{array}{l}0.8 \text { Frutas, } \\
\text { cascas de } \\
\text { cítricos e } \\
\text { melões }\end{array}$ & 0,97 & 0,97 & 0,98 & 0,97 & 0,96 & 0,96 & 0,96 & 0,95 & 0,93 & 0,96 & 0,97 \\
\hline $\begin{array}{l}\text { 17. Açúcares } \\
\text { e produtos de } \\
\text { confeitaria }\end{array}$ & 0,76 & 0,74 & 0,65 & 0,61 & 0,66 & 0,55 & 0,44 & 0,44 & 0,21 & 0,39 & 0,45 \\
\hline $\begin{array}{l}\text { 25. Sal, } \\
\text { enxofre, terras, } \\
\text { pedras, gesso, } \\
\text { cal, cimento }\end{array}$ & 0,77 & 0,86 & 0,90 & 0,87 & 0,84 & 0,85 & 0,79 & 0,65 & 0,45 & 0,74 & 0,77 \\
\hline $\begin{array}{l}27 . \\
\text { Combustíveis, } \\
\text { óleos e ceras } \\
\text { minerais etc. }\end{array}$ & - & - & - & - & - & - & 0,38 & 0,57 & 0,83 & 0,59 & 0,0 \\
\hline 52. Algodão & 0,75 & 0,84 & 0,82 & 0,83 & 0,59 & 0,58 & 0,59 & 0,55 & 0,42 & 0,64 & 0,69 \\
\hline $\begin{array}{l}\text { 61. Vestuário } \\
\text { e seus } \\
\text { acessórios, de } \\
\text { malha }\end{array}$ & - & 0,64 & 0,93 & 0,95 & 0,97 & 0,97 & 0,96 & 0,89 & 0,82 & 0,89 & 0,89 \\
\hline
\end{tabular}

FONTE: Elaboração dos autores. Dados disponibilizados pelo MDIC/SECEX, sistema ALICEWEB. As mercadorias estão classificadas por grupos de produtos de acordo com a Nomenclatura Comum do Mercosul (NCM). O símbolo (-) sigunifica ausência de exportações.

A Tabela 7 apresenta resultados da aplicação do índice de comércio intra-indústria por grupos de produtos. Entre os produtos com vantagens comparativas, o algodão foi aquele que apresentou maiores indicadores de comércio intra-industrial. Para os demais, os escores se aproximaram de zero, marcando as características do comércio interindustrial. A presença de comércio intra-industrial no grupo de algodão revela um comércio de mão-dupla, ou seja, o Estado tanto exporta como importa esse produto. 
Tabela 6 - Índice de comércio intra-indústria agregado - Brasil, Nordeste, Pernambuco e Rio Grande do Norte (1996-2006).

\begin{tabular}{ccccc}
\hline Anos & Brasil & Nordeste & Pernambuco & Rio Grande do Norte \\
\hline 1996 & 0,43 & 0,55 & 0,18 & 0,06 \\
1997 & 0,45 & 0,23 & 0,18 & 0,06 \\
1998 & 0,47 & 0,27 & 0,18 & 0,07 \\
1999 & 0,45 & 0,28 & 0,20 & 0,08 \\
2000 & 0,46 & 0,27 & 0,22 & 0,05 \\
2001 & 0,47 & 0,34 & 0,16 & 0,05 \\
2002 & 0,47 & 0,34 & 0,18 & 0,05 \\
2003 & 0,47 & 0,42 & 0,21 & 0,03 \\
2004 & 0,45 & 0,40 & 0,26 & 0,05 \\
2005 & 0,49 & 0,39 & 0,28 & 0,07 \\
2006 & 0,52 & 0,32 & 0,26 & 0,08 \\
\hline
\end{tabular}

Fonte: Elaboração dos autores a partir dos dados disponibilizados pelo Ministério do Desenvolvimento, da Indústria e do Comércio - MDIC/ SECEX.

Gráfico 3 - Indicador do comércio interindustria do Rio Grande do Norte (1996-2006)

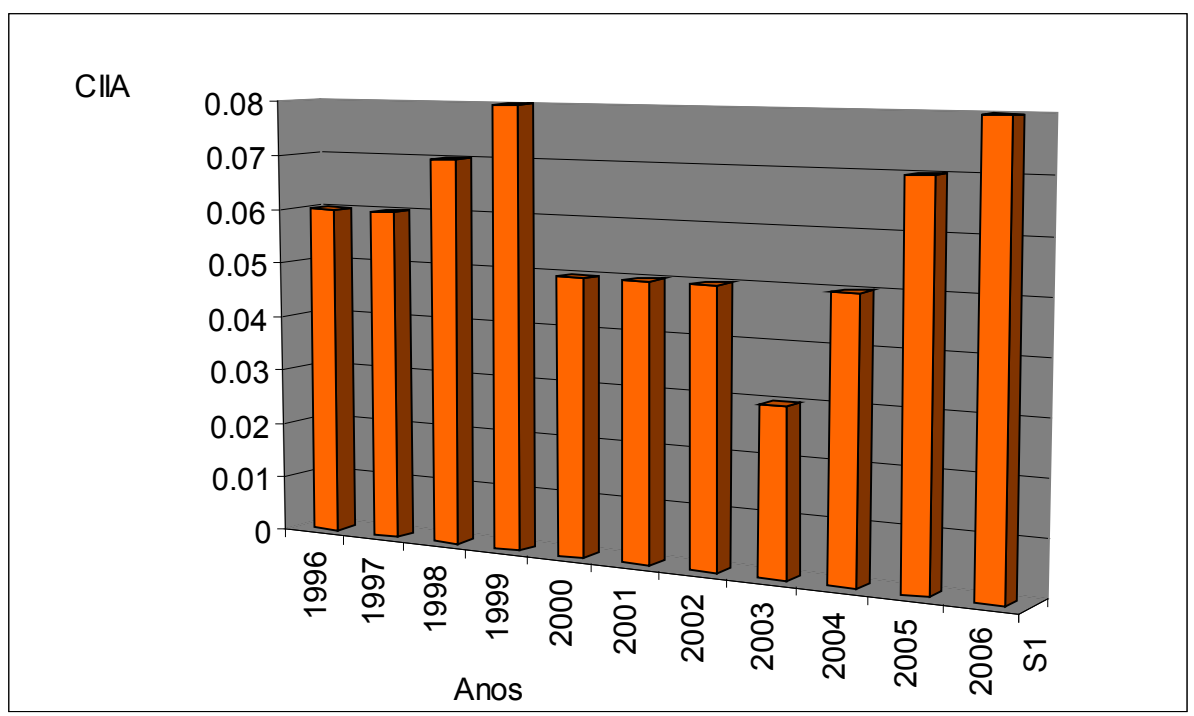

Fonte: Elaboração dos autores. Dados disponibilizados pelo MDIC/SECEX, Sistema ALICEWEB. 
Esse fato pode ser explicado tanto pela retomada da cultura do algodão na região semi-árida do Estado como também pelo crescimento do setor têxtil, com a atração de novas indústrias e a expansão daquelas já instaladas. Com isso, o setor vem aumentando sua demanda pelo algodão da região, e ainda elevando as importações desse produto.

Tabela 7 - Índice do Comércio Intra-Indústria para os produtos com vantagens comparativas reveladas. Rio Grande do Norte (1996-2005)

\begin{tabular}{|c|c|c|c|c|c|c|c|c|c|c|c|}
\hline \multirow{2}{*}{ Capítulos } & \multicolumn{11}{|c|}{ Índice de comércio intra-indústria - CIIA } \\
\hline & 1996 & 1997 & 1998 & 1999 & 2000 & 2001 & 2002 & 2003 & 2004 & 2005 & 2006 \\
\hline $\begin{array}{l}\text { 03. Peixes e } \\
\text { Crustáceos, } \\
\text { moluscos, etc }\end{array}$ & 0,20 & 0,23 & 0,32 & 0,03 & 0,01 & 0,01 & 0,01 & 0,0 & 0,0 & 0,01 & 0,01 \\
\hline $\begin{array}{l}08 \text {. Frutas; } \\
\text { cascas de } \\
\text { cítricos e melões }\end{array}$ & 0,01 & 0,01 & 0,0 & 0,0 & 0,0 & 0,0 & 0,0 & 0,0 & 0,0 & 0,0 & 0,0 \\
\hline $\begin{array}{l}\text { 17. Açúcares } \\
\text { e produtos de } \\
\text { confeitaria }\end{array}$ & 0,0 & 0,0 & 0,02 & 0,05 & 0,02 & 0,01 & 0,02 & 0,0 & 0,0 & 0,0 & 0,01 \\
\hline $\begin{array}{l}\text { 25. Sal; enxofre; } \\
\text { terras, pedras; } \\
\text { gesso, cal, } \\
\text { cimento }\end{array}$ & 0,0 & 0,02 & 0,02 & 0,01 & 0,01 & 0,0 & 0,0 & 0,0 & 0,0 & 0,01 & 0,01 \\
\hline $\begin{array}{l}27 . \\
\text { Combustíveis, } \\
\text { óleos e ceras } \\
\text { minerais etc. }\end{array}$ & - & - & - & - & - & - & 0,02 & 0,01 & 0,0 & 0,0 & 0,0 \\
\hline 52. Algodão & 0,44 & 0,15 & 0,25 & 0,71 & 0,42 & 0,86 & 0,96 & 0,86 & 0,84 & 0,41 & 0,54 \\
\hline $\begin{array}{l}\text { 61. Vestuário e } \\
\text { seus acessórios } \\
\text { de malha. }\end{array}$ & 0,0 & 0,0 & 0,0 & 0,0 & 0,04 & 0,0 & 0,0 & 0,0 & 0,0 & 0,03 & 0,01 \\
\hline
\end{tabular}

FONTE: Elaboração dos autores. Dados disponibilizados pelo MDIC/SECEX, sistema ALICEWEB. As mercadorias estão classificadas por grupos de produtos de acordo com a Nomenclatura Comum do Mercosul (NCM).

A fim de identificar os setores fortes do Rio Grande do Norte no comércio exterior, utilizou-se o critério desenvolvido por GUTMAN e MIOTTI (1996), que definiram como setores fortes aqueles produtos 
que apresentassem vantagem comparativa revelada e, ao mesmo tempo, taxa de cobertura maior que a unidade. Entende-se por taxa de cobertura de um determinado produto o coeficiente entre as exportações $\mathrm{X}_{\mathrm{i}}$ e importações $\mathrm{M}_{\mathrm{i}}$ de um mesmo produto por um determinado país ou região.

Taxa de Cobertura $=\boldsymbol{X}_{i} / \boldsymbol{M}_{\boldsymbol{i}}$

A Tabela 8, a ser contemplada, mostra taxas de cobertura dos setores com vantagem comparativa no comércio exterior do Rio Grande do Norte. Essas informações permitem identificar os setores fortes do Estado no comércio exterior. Embora o Rio Grande do Norte possua vantagem comparativa na exportação do algodão, ele não pode ser considerado um setor forte no comércio exterior porque a sua taxa de cobertura não foi superior à unidade em todos os anos do período analisado. Isso posto, os grupos de produtos que podem ser considerados fortes no comércio exterior do Estado, com base nesse critério de GUTMAN e MIOTTI (1996), são os seguintes: 1) peixes e crustáceos, moluscos etc. 2) frutas, cascas de cítricos e de melões; 3) açúcares e produtos de confeitaria; 4) sal, enxofre, terras, pedras, gesso, cal, cimento; 5) combustíveis, óleos e ceras minerais; e 6) vestuário e seus acessórios de malha.

A comparação dos setores fortes de uma economia (país ou região) com os setores fracos de cada um dos parceiros comerciais permite conhecer o grau de aproveitamento e adaptação da oferta dos produtos de um país à demanda internacional. Além do mais, o não aproveitamento de vantagens existentes pode ocorrer devido à existência de barreiras comerciais (tarifárias e não tarifárias) ou, ainda, devido à existência de sistemas ou acordos preferenciais de comércio.

No caso do Rio Grande do Norte, a aplicação de políticas de antidumping ao camarão brasileiro, por parte dos Estados Unidos, limitou a exportação para esse mercado, contribuindo, dessa forma, para a queda das exportações no ano de 2003. Entre 2004 e 2005, as exportações de camarão voltam a sofrer outro impacto, induzido pelo declínio do preço externo. Quanto às frutas, também existem requisitos fitossanitários para a sua exportação em alguns mercados, principalmente o da União 
Européia e do NAFTA. Por outro lado, os subsídios ao setor agrícola nos países desenvolvidos também limitam as exportações agrícolas, pois a produção local ou nacional tem que concorrer em desvantagem. Da mesma forma, os sistemas de preferências concedidos a alguns países, principalmente aos menos desenvolvidos, por parte da Comunidade Econômica Européia e dos Estados Unidos (Convenção de Lomé e Iniciativa da Bacia do Caribe), diminuem a capacidade do Estado de competir nesses mercados, pois esses países são também produtores de bens tropicais, entre outros.

Tabela 8 - Taxa de cobertura para os produtos com vantagens comparativas reveladas. Rio Grande do Norte (1996-2005)

\begin{tabular}{|c|c|c|c|c|c|c|c|c|c|c|c|}
\hline \multirow{2}{*}{ Capítulos } & \multicolumn{11}{|c|}{ Taxa de cobertura } \\
\hline & 1996 & 1997 & 1998 & 1999 & 2000 & 2001 & 2002 & 2003 & 2004 & 2005 & 2006 \\
\hline $\begin{array}{l}03 \text {. Peixes } \\
\text { e crus- } \\
\text { táceos, } \\
\text { moluscos, } \\
\text { etc. }\end{array}$ & 9,0 & 7,6 & 5,2 & 56,9 & 138,7 & 138,9 & 287,0 & 489,1 & 646,3 & 392,1 & 147,0 \\
\hline $\begin{array}{l}\text { 08. Fru- } \\
\text { tas, cas- } \\
\text { cas de } \\
\text { cítricos e } \\
\text { de melóes }\end{array}$ & 194,1 & 285,3 & 282,2 & 1953 & 1805 & 2270 & $\#$ & $\#$ & 1322 & $\#$ & $\#$ \\
\hline $\begin{array}{l}\text { 17. Açú- } \\
\text { cares e } \\
\text { produtos } \\
\text { de confei- } \\
\text { taria }\end{array}$ & 814,1 & 415,2 & 121,9 & 35,7 & 85,9 & 349,4 & 129,4 & $\#$ & $\#$ & \# & $\#$ \\
\hline $\begin{array}{l}\text { 25. Sal, } \\
\text { enxofre, } \\
\text { terras, } \\
\text { pedras, } \\
\text { gesso, cal, } \\
\text { cimento }\end{array}$ & 386355 & 108 & 119 & 211 & 204 & 185 & 647 & 764 & 411 & 496 & 326,5 \\
\hline $\begin{array}{l}27 . \text { Com- } \\
\text { bustíveis, } \\
\text { óleos e ce- } \\
\text { ras mine- } \\
\text { rais etc. }\end{array}$ & - & - & - & - & - & - & 93,2 & 140,9 & 979,1 & 440,1 & $121.448,8$ \\
\hline
\end{tabular}




\begin{tabular}{lllllllllllll}
\hline $\begin{array}{l}\text { 52. Algo- } \\
\text { dão } \\
\begin{array}{l}\text { 61. Ves- } \\
\text { tuário e }\end{array}\end{array}$ & 0,3 & 0,1 & 0,1 & 0,6 & 0,3 & 0,8 & 1,1 & 1,3 & 0,7 & 3,9 & 0,5 \\
$\begin{array}{l}\text { seus aces- } \\
\text { sórios, de } \\
\text { malha }\end{array}$ & - & 532,3 & $\#$ & $\#$ & 55,8 & 419,9 & $\#$ & 2619 & 832.853 & 65,8 & 55,5 \\
\hline
\end{tabular}

FONTE: Elaboração dos autores. Dados disponibilizados pelo MDIC/SECEX, sistema ALICEWEB. As mercadorias estão classificadas por grupos de produtos de acordo com a Nomenclatura Comum do Mercosul (NCM).

Nota: o símbolo \# significa ausência de importações e (-) ausência de exportações do grupo de produtos naquele ano.

\section{Conclusões}

No presente trabalho, procurou-se analisar as exportações do Rio Grande do Norte sob a ótica de indicadores de vantagens comparativas. Foram mensurados índices de vantagens comparativas reveladas, índices de concentração das exportações, por produtos e destinos, e foram identificados os setores fortes do Estado no comércio exterior. Embora as exportações do Rio Grande do Norte tenham exibido, nesses últimos anos, significativas taxas de crescimento, também apresentaram uma alta concentração em poucos produtos primários e poucos países de destino. Além disso, ficou evidenciado que o comércio internacional do Estado é basicamente interindustrial, do tipo Heckscher-Ohlin.

Os produtos que mostraram maior crescimento nas exportações são de origem primária, como frutas, cascas de cítricos e de melões; peixes e crustáceos; e, com uma maior dinâmica nestes últimos quatro anos, combustíveis, óleos e derivados. Já o desempenho das exportações de manufaturados no Rio Grande do Norte é ínfimo. Isso reflete o fraco desenvolvimento e a fraca modernização das indústrias no Estado, o que demandaria uma política de estímulo à produção, garantias, subsídios e desenvolvimento de uma vocação exportadora de produtos manufaturados.

Por último, deve-se esclarecer que, dentre alguns setores que exibiram indicadores de vantagens comparativas (tais como frutas, cascas de cítricos e de melões; açúcares e produtos de confeitaria; algodão; sal e sucedâneos; vestuário e seus acessórios de malha) verificou-se, ao longo do período analisado, uma tendência declinante nesses indicadores. 
Dessa forma, políticas de apoio à modernização desses setores poderiam ser empregadas pelos governos estadual e federal, no sentido de recuperar suas vantagens comparativas no comércio internacional.

\section{Referências}

BALASSA, B. Trade liberalization and revealed comparative advantage. Washington, D.C.: Banco Mundial, 1965.

FARIAS, J. J. Exportações do Rio Grande do Norte: Crescimento, Vantagens Comparativas Reveladas e o Problema da Concentração (19801995). Dissertação de Mestrado. (Mimeo) UFPE -PIMES, Recife, 2000.

GRUBEL, H.; LLOYD, P. Intra-Industry Trade: the theory and the measurement of international trade in differentiated products. London: Macmillan, 1975.

GUTMAN, G. E.; MIOTTI, L. Exportaciones agroindustriales de América Latina y el Caribe: Especialización, competitividad y oportunidades comerciales en los mercados de la OCDE. Local [s.l.] : CEPAL, 1996.

HIDALGO, A. B.; MATA, D. F. P. G. da. A especialização do nordeste brasileiro e do Estado de Pernambuco no comércio exterior. Recife: PIMES/ Departamento de Economia, 2003. 32p. (texto para discussão, 465).

. Exportações do Estado de Pernambuco: concentração, mudança na estrutura e perspectivas. Revista Econômica do Nordeste. Fortaleza, v.35, n.2, p. 264-283, abr./jun. 2004.

LAURSEN K. Revealad Comparative Advantage and the Alternatives as Measures of International Specialization. Working Paper, n. 98-30, Copenhagen: Danish Rearch Unit for Dynamics, 1998.

LOVE, J.. Trade concentration and export instability. The Journal of Development Studies, v.15, n.3, p. 60-69, 1979.

MINISTÉRIO DO DESENVOLVIMENTO, INDÚSTRIA E COMÉRCIO EXTERIOR. Secretaria de Comércio Exterior (MDIC/SECEX). Dados sobre o comércio exterior brasileiro. Disponível em: http://www. aliceweb.desenvolvimento.gov.br. Acesso em janeiro/março. 2007. 